\title{
Lesões Induzidas por Papilomavirus Humano em Parceiros de Mulheres com Neoplasia Intra-Epitelial do Trato Genital Inferior
}

\author{
Papillomavirus-Induced Lesion in Partners of Womem with Intraepithelial Neoplasia of the Lower
} Genital Tract

\author{
Júlio César Teixeira, César Cabello dos Santos \\ Sophie Françoise Mauricette Derchain, Luiz Carlos Zeferino
}

\begin{abstract}
RESUMO
Objetivos: pesquisar a presença de lesões induzidas por papilomavirus (HPV) e os fatores associados em parceiros de mulheres com neoplasia intra-epitelial genital.

Métodos: foram avaliados 337 homens por meio de citologia uretral, peniscopia e biópsia, quando necessário. Analisou-se a presença de lesão induzida por HPV correlacionando-a com a idade, escolaridade, tabagismo, estabilidade conjugal, inicio da atividade sexual, número de parceiras, antecedente de doença sexualmente transmissivel (DST), postectomia, imagens peniscópicas e grau das lesões nas mulheres.

Resultados: a peniscopia foi positiva em 144 homens (42,7\%) e 105 (31,2\%) apresentaram lesões induzidas por HPV. Somente o tabagismo, a estabilidade conjugal menor ou igual a seis meses e o antecedente de mais de uma parceira sexual estiveram associados com a presença de lesão induzida por HPV $(p<0,05)$. A citologia uretral foi suspeita para HPV em 4,2\% dos casos, sendo este achado significativamente associado com tabagismo, peniscopia ou biópsias positivas e com parceiros de mulheres com lesão de alto grau. Das 229 biópsias realizadas, $72,1 \%$ foram positivas para $H P V$, independentemente da imagem peniscópica e do grau de lesão na mulher.

Conclusões: as lesões induzidas por HPV foram diagnosticadas em 31,2\% dos casos e estiveram associadas com o tabagismo, tempo de união conjugal menor ou igual a seis meses e mais de uma parceira sexual. O grau de lesão na mulher, escolaridade, antecedente de DST, postectomia e imagem peniscópica não se mostraram correlacionados com a presença de lesão induzida por HPV.
\end{abstract}

PALAVRAS-CHAVE: Peniscopia. HPV. Colo: lesões pré-neoplásicas. Pênis: neoplasia intraepitelial.

\section{Introdução}

A infecção pelo papilomavirus (HPV) talvez seja hoje a doença sexualmente transmissivel (DST)

Área de Oncologia Ginecológica e Patologia Mamária do Departamento de Tocoginecologia da Faculdade de Ciências Médicas e Centro de Atenção Integral à Saúde da Mulher (CAISM) da Universidade Estadual de Campinas (UNICAMP). Correspondência:

Júlio César Teixeira

Assessoria Técnica e Científica do CAISM/UNICAMP

Rua Alexander Fleming, 101 - Cidade Universitária "Zeferino Vaz" 13.083-970 - Campinas - SP

Fone: (19) 788-9402 - Fax: (19) 289-5935 e 289-3687.

e-mail: julioc@bestway.com.br mais comum. É também um importante fator envolvido no desenvolvimento de câncer no trato genital feminino. O HPV pode persistir no organismo por muitos anos, latente ou provocando lesões assintomáticas, e o homem apresenta-se como elemento-chave na disseminação deste virus ${ }^{1,2}$.

A pesquisa de infecção pelo HPV no homem é realizada mediante peniscopia com o auxílio do ácido acético a 5\%. É um exame pouco específico e as imagens identificadas apresentam pouca correlação com o achado histopatológico. Desta forma, diagnosticam-se lesões induzidas por HPV em tecido de biópsia, entre 30 e $55 \%$ dos parceiros de mulheres com lesões induzidas por HPV, taxa 
esta menor que a esperada $a^{3,4,5,6}$. Mesmo assim, acredita-se que o diagnóstico e o tratamento das lesões pelo HPV no homem poderiam diminuir o risco de reinfecção ou de recidivas na mulher ${ }^{3,7,8,9}$.

O objetivo deste estudo foi avaliar a freqüência de lesões relacionadas ao HPV nos parceiros de mulheres com neoplasia intra-epitelial do trato genital inferior por meio da peniscopia, citologia e histologia. Também foram avaliados os fatores de risco associados.

\section{Pacientes e Métodos}

Este estudo clínico foi realizado com 337 homens atendidos na Área de Oncologia Genital do Centro de Atenção Integral à Saúde da Mulher (CAISM) da Universidade Estadual de Campinas (UNICAMP), entre janeiro de 1994 e novembro de 1998. Todos eram parceiros, por pelo menos seis meses, de mulheres atendidas no mesmo ambulatório por apresentarem neoplasia intra-epitelial do trato genital inferior associada a sinais citológicos ou histológicos de infecção por HPV.

Os pacientes eram orientados sobre o que estava ocorrendo com sua parceira e recebiam uma noção geral de como se adquire, se transmite, se previne uma infecção pelo HPV e as suas possiveis repercussões. Eram, então, submetidos a uma anamnese dirigida e a exame clínico que consistia de avaliação macroscópica preliminar da região peniana, escrotal, crural e perineal; colheita de material da uretra distal por meio da introdução e rotação de cotonete com lidocaína gel, o qual era processado para avaliação citológica pela técnica de Papanicolaou; depois procedia-se à aplicação de ácido acético a $5 \%$ por cerca de três minutos em toda a região genital e avaliação com o colposcópio com aumentos entre 6 e 14 vezes. Os achados eram anotados em ficha esquematizada com especial atenção para o tipo de imagem, localização, tamanho e número das lesões.

$\mathrm{Na}$ primeira avaliação, muitos pacientes apresentavam sinais de balanopostites resultando em imagens peniscópicas confundidoras. Foram orientados quanto aos cuidados locais e a retornarem após 15 dias para reavaliação, quando se observou que a maioria das lesões havia desaparecido. As lesões persistentes e suspeitas eram biopsiadas utilizando-se anestesia local com injeção de lidocaína a 1\%, pinça e tesoura de íris, e os fragmentos, a maioria em torno de $2 \mathrm{~mm}$, eram fixados em formol a 10\% e enviados para avaliação histopatológica. As feridas eram deixadas abertas ou eletrocauterizadas. O diagnóstico de lesão induzida por HPV foi considerado na presença de atipias coilocitóticas na citologia ou histologia ${ }^{10,11}$.

Foram avaliados a idade dos pacientes, grau de escolaridade, hábito de fumar, tempo de estabilidade conjugal, ou seja, o intervalo de tempo em que o homem mantinha relações sexuais apenas com a parceira atual, a idade à primeira relação sexual, o número de parceiras sexuais e os antecedentes de DST e de postectomia. Também foram avaliados os achados peniscópicos e o grau das lesões nas mulheres. Esta variáveis foram correlacionadas com a presença de lesão induzida por HPV na histologia e na citologia uretral. As informações coletadas foram digitadas em um banco de dados utilizando o programa Epi Info ${ }^{12}$ para microcomputador. Para análise estatística foram utilizados os testes de $\chi^{2}$, exato de Fisher e $t$ de Student, com nivel de significância estatística de $5 \%$.

\section{Resultados}

A média de idade do grupo estudado de 337 pacientes foi de 31 anos (17-53). Com a peniscopia foram detectados alguns achados suspeitos em 144 pacientes $(42,7 \%)$ e a presença de lesão histológica ou citológica induzida por HPV foi confirmada em $105(31,2 \%)$. Os dados epidemiológicos e fatores de risco estão na Tabela 1 . O tabagismo esteve associado significativamente às manifestações da infecção por HPV, pois quase metade dos pacientes que fumavam e apenas um quarto daqueles que não fumavam apresentaram lesão induzida por HPV ( $p=0,0005)$. Quando avaliamos o tempo médio de união conjugal, verificamos que este foi menor para o grupo com HPV (41 meses) em comparação com os homens sem doença (56 meses, $p=0,017$ ). Enquanto $45 \%$ dos homens que referiram até seis meses de estabilidade conjugal tinham lesão induzida por HPV, apenas 20,7\% dos que estavam estáveis há mais de dois anos tiveram a infecção diagnosticada $(p=0,0008)$. Um terço dos homens que relataram mais de uma parceira sexual, independentemente do número, e apenas $9,1 \%$ daqueles que tiveram relação sexual apenas com a parceira atual tinham HPV $(\mathrm{p}=0,038)$. A escolaridade de nível superior relatada por 126 $(37,4 \%)$, a idade ao início sexual - 292 pacientes $(86,6 \%)$ referiram um início até 19 anos - e os antecedentes de DST, que ocorreu em 92 pacientes $(27,3 \%)$, e de postectomia, em 69 (20,5\%), não estiveram associados ao diagnóstico de lesão induzida por HPV. 
Tabela 1 - Correlação entre o diagnóstico de lesão peniana pelo HPV em 337 parceiros de mulheres com neoplasia intra-epitelial genital e algumas variáveis.

\begin{tabular}{|c|c|c|c|}
\hline \multirow[b]{2}{*}{ Variável } & \multicolumn{2}{|c|}{ Lesão por HPV } & \multirow[b]{2}{*}{$p$} \\
\hline & Sim & Não & \\
\hline Idade em anos (média) & $30,5(19-53)$ & $31,5(17-55)$ & 0,27 \\
\hline \multicolumn{4}{|l|}{ Escolaridade superior } \\
\hline $\operatorname{Sim}(\%)$ & $38(30,2)$ & $88(69,8)$ & \\
\hline Não (\%) & $67(31,8)$ & $144(68,2)$ & 0,76 \\
\hline \multicolumn{4}{|l|}{ Hábito de fumar } \\
\hline $\operatorname{Sim}(\%)$ & $44(44,9)$ & $54(55,1)$ & \\
\hline Não (\%) & $61(25,5)$ & $178(74,5)$ & 0,0005 \\
\hline Cigarros/dia & $19(2-40)$ & $18(5-50)$ & 0,68 \\
\hline Tempo em anos & $12,9(1-35)$ & $13,8(2-40)$ & 0,59 \\
\hline \multicolumn{4}{|l|}{ Estabilidade conjugal } \\
\hline 0 a 6 meses $(\%)$ & $18(45,0)$ & $22(55,0)$ & \\
\hline 7 a 12 meses (\%) & $22(38,6)$ & $35(61,4)$ & \\
\hline 13 a 24 meses $(\%)$ & $31(40,8)$ & $45(59,2)$ & \\
\hline$>24$ meses $(\%)$ & $34(20,7)$ & $130(79,3)$ & 0,0008 \\
\hline Média em meses & $41(0-348)$ & $56(0-324)$ & 0,017 \\
\hline \multicolumn{4}{|l|}{ Idade ao início sexual } \\
\hline 12 a 15 anos (\%) & $38(34,5)$ & $72(65,5)$ & \\
\hline 16 a19 anos (\%) & $56(30,8)$ & $126(69,2)$ & \\
\hline$>20$ anos $(\%)$ & $11(24,4)$ & $34(75,6)$ & 0,46 \\
\hline Média em anos & $16,7(12-33)$ & $16,9(12-30)$ & 0,52 \\
\hline \multicolumn{4}{|l|}{ Número de parceiras } \\
\hline $1(\%)$ & $2(9,1)$ & $20(90,9)$ & \\
\hline 2 a $5(\%)$ & $35(30,2)$ & $81(69,8)$ & \\
\hline 6 a $10(\%)$ & $33(35,9)$ & $59(64,1)$ & \\
\hline$>10(\%)$ & $35(32,7)$ & $72(67,3)$ & $0,038^{*}$ \\
\hline \multicolumn{4}{|l|}{ Antecedente de DST } \\
\hline $\operatorname{Sim}(\%)$ & $3 \mathbb{1}^{\#}(33,7)$ & $61^{\#}(66,3)$ & \\
\hline Não (\%) & $74(30,2)$ & $171(69,8)$ & 0,53 \\
\hline \multicolumn{4}{|l|}{ Postectomia } \\
\hline $\operatorname{Sim}(\%)$ & $23(33,3)$ & $46(66,7)$ & \\
\hline Não (\%) & $82(30,6)$ & $186(69,4)$ & 0,66 \\
\hline Sintomático & $32(57,1)$ & $24(42,9)$ & \\
\hline Assintomático & $73(26,0)$ & $208(74,0)$ & $<0,0001$ \\
\hline
\end{tabular}

A citologia uretral apresentou alguma alteração sugestiva de infecção por HPV em dez pacientes $(4,2 \%)$, todos sem lesões visíveis na uretra ao colposcópio (Tabela 2). Este sinal de lesão induzida por HPV na uretra, sistema urinário ou reprodutivo baixo foi três vezes mais freqüente nos homens que fumavam $(p=0,03)$. A alteração citológica uretral também esteve associada com a presença de imagens suspeitas à peniscopia $(\mathrm{p}=0,07)$, com diagnóstico histológico de infecção por HPV na biópsia dos órgãos genitais externos $(p=0,05)$ e com o diagnóstico de lesão intra-epitelial de alto grau (LIE-AG) na parceira $(p=0,005)$. O tempo de estabilidade conjugal e o antecedente de postectomia não estiveram relacionados com o resultado da citologia uretral. Entre os dez pacientes com citologia uretral suspeita, dois referiram algum sintoma na anamnese: um referia o surgimento de verrugas genitais e o outro uma disúria esporádica, e ambos tiveram o diagnóstico de lesão induzida por HPV na biópsia peniana. Destes dez pacientes, seis foram submetidos a algum tratamento pelas lesões induzidas por HPV em órgãos genitais externos. No primeiro controle após três meses, os dez pacientes com citologia uretral positiva estavam assintomáticos e apresentavam peniscopia e citologia uretral negativas, não necessitando nenhuma avaliação uretral mais detalhada.

Tabela 2 - Correlação entre o resultado da citologia uretral em 337 parceiros de mulheres com neoplasia intra-epitelial genital e algumas variáveis.

\begin{tabular}{lcrc}
\hline & \multicolumn{3}{c}{ Citologia uretral (\%) } \\
\cline { 2 - 4 } Variáveis & Suspeita para HPV & Negativa & p \\
\hline Sintoma clínico & & & \\
Sim & $2(3,6)$ & $54(96,4)$ & \\
Não & $8(2,8)$ & $273(97,2)$ & 0,52 \\
Estabilidade conjugal & & & \\
O a 6 meses & $1(2,5)$ & $39(97,5)$ & \\
$>6$ meses & $9(3,0 \%)$ & $288(97,0)$ & 0,66 \\
Hábito de fumar & & & \\
Sim & $6(6,1)$ & $92(93,9)$ & \\
Não & $4(1,7)$ & $235(98,3)$ & 0,03 \\
Postectomia & & & \\
Sim & $1(1,4)$ & $68(98,6)$ & \\
Não & $9(3,4)$ & $259(96,6)$ & 0,35 \\
Peniscopia & & & \\
Positiva & $7(4,9)$ & $137(95,1)$ & \\
Negativa & $3(1,6)$ & $190(98,4)$ & 0,07 \\
Homem com HPV & & & \\
Sim & $6(5,7)$ & $99(94,3)$ & \\
Não & $4(1,7)$ & $228(98,3)$ & 0,05 \\
Lesão na mulher & & & \\
Baixo grau & $4(1,5)$ & $265(98,5)$ & \\
Alto grau & $6(8,8)$ & 62,005 \\
\hline
\end{tabular}

Realizamos biópsias de 229 lesões em 144 pacientes (88 pacientes com apenas uma biópsia), sendo 172 biópsias de lesões subclínicas. Cerca de $70 \%$ das biópsias foram positivas para lesão induzida por HPV. Nas demais 30\% o principal achado foi de hiperqueratose. O tipo de imagem peniscópica não se relacionou com o diagnóstico histológico (Tabela 3). Dos seis casos de neoplasia intra-epitelial peniana (NIP), cinco se apresentaram como lesões subclínicas e nenhum como pápula hipercrômica. 
Tabela 3 - Correlação entre o tipo de imagem peniscópica e o resultado histopatológico em 229 biópsias penianas.

\begin{tabular}{|c|c|c|c|c|c|c|c|c|c|}
\hline Histopatologia & Mácula & Pápula & $\begin{array}{l}\text { Pápula } \\
\text { anular }\end{array}$ & $\begin{array}{l}\text { Espículas } \\
\text { agrupadas }\end{array}$ & $\begin{array}{l}\text { Micro- } \\
\text { papilar }\end{array}$ & Outras & $\begin{array}{c}\text { Condiloma papular } \\
\text { ou acuminado }\end{array}$ & $\begin{array}{c}\text { Pápula } \\
\text { hipercrômica }\end{array}$ & Total (\%) \\
\hline Sem alterações & - & - & - & $1(8,3)$ & - & - & - & - & $1(0,4)$ \\
\hline Condiloma plano & $9(60,0)$ & $79(65,3)$ & $5(45,5)$ & $8(66,7)$ & $10(100)$ & - & $14(40,0)$ & $16(72,8)$ & $141(61,6)$ \\
\hline Cond. Acuminado & - & $2(1,7)$ & - & - & - & - & $14(40,0)$ & $2(9,1)$ & $18(7,9)$ \\
\hline NIP & $1(6,7)$ & $4(3,3)$ & - & - & - & - & $1(2,9)$ & - & $6(2,6)$ \\
\hline Hiperqueratose & $5(33,3)$ & $28(23,1)$ & $5(45,5)$ & $2(16,7)$ & - & - & $1(2,9)$ & $1(4,5)$ & $42(18,4)$ \\
\hline Outros & - & - & $1^{*}(9,0)$ & - & - & $1^{\#}(33,3)$ & $2^{*}(5,7)$ & $2^{+}(9,1)$ & $6(2,6)$ \\
\hline Total (\%) & $15(6,6)$ & $121(52,8)$ & $11(4,8)$ & $12(5,2)$ & $10(4,4)$ & $3(1,3)$ & $35(15,3)$ & $22(9,6)$ & $229(100,0)$ \\
\hline
\end{tabular}

Obs.: NIP = neoplasia intra-epitelial peniana.

*Molusco

\#Vitiligo

+Nevo

Quando avaliamos o achado de lesão induzida por HPV no homem e sua correlação com o grau de lesão na mulher, não observamos associação significativa. Na Tabela 4, observamos que 43,8\% dos parceiros de mulheres com neoplasia intraepitelial cervical (NIC) grau III e 30,1\% dos parceiros de mulheres com lesão intra-epitelial de baixo grau (LIE-BG) foram positivos para HPV. Observamos, entretanto, que o resultado histopatológico das biópsias penianas foi compativel com lesão induzida por HPV em $82,5 \%$ dos parceiros de mulheres com LIE-AG e apenas 7,5\% apresentavam hiperqueratose. Entre os resultados de biópsia realizada nos parceiros de mulheres com LIE-BG, 69,8\% apresentavam alterações sugestivas de lesões induzidas por HPV e $20,6 \%$ de hiperqueratose. Observamos também que dos seis casos de NIP, cinco ocorreram em parceiros de mulheres com LIE-BG (Tabela 5).

Tabela 4 - Correlação entre o grau da neoplasia intra-epitelial genital na mulher e o diagnóstico de lesão peniana pelo HPV em 337 parceiros avaliados.

\begin{tabular}{|c|c|c|c|c|c|c|}
\hline \multirow[b]{2}{*}{ HPV no homem } & \multicolumn{3}{|c|}{ Baixo grau } & \multicolumn{3}{|c|}{ Alto grau } \\
\hline & NIC I & NIVA I e/ou NIV I & Total & NIC II ou NIVA II & NIC III ou NIV III & Total \\
\hline Sim & $62^{+}(32,0)$ & $19(25,3)$ & $81(30,1)$ & $10(27,8)$ & $14^{*}(43,8)$ & $24(35,3)$ \\
\hline Total & $194(100,0)$ & $75(100,0)$ & $269(100,0)$ & $36(100,0)$ & $32(100,0)$ & $68(100,0)$ \\
\hline
\end{tabular}

$p=0,28$. Obs.: $\mathrm{NI}=$ neoplasia intra-epitelial; $\mathrm{C}=$ cervical; $\mathrm{VA}=$ vaginal; $\mathrm{V}=$ vulvar.

+21 com NIVA I ou NIV I

\# 2 NIVA II

*1 NIV III

A presença de lesão clínica (macroscópica) esteve associada à detecção de lesões subclínicas em 90,2\% dos casos. De 281 pacientes assintomáticos, apenas $5,7 \%$ tinham lesões

Tabela 5 - Correlação entre o grau da lesão genital na mulher e o resultado de 229 biópsias penianas nos parceiros avaliados.

\begin{tabular}{lrr}
\hline & \multicolumn{2}{c}{ Lesão intra-epitelial na mulher (\%) } \\
\hline Biópsia peniana & Baixo grau & Alto grau \\
\hline Condiloma plano & $127(67,2)$ & $32(80,0)$ \\
Ou acuminado & & \\
NIP & $5(2,6)$ & $1(2,5)$ \\
Hiperqueratose & $39(20,6)$ & $3(7,5)$ \\
Outros & $18(9,5)$ & $4(10,0)$ \\
Total $(n=229)$ & $189(100,0)$ & $40(100,0)$ \\
\hline
\end{tabular}

$p=0,26$. Obs.: NIP $=$ neoplasia intra-epitelial peniana. macroscópicas à avaliação clínica, ao passo que $66,1 \%$ de sintomáticos apresentaram peniscopia positiva (Tabela 6).

Tabela 6 - Correlação entre a presença de sintomas específicos e o resultado da peniscopia em 337 homens avaliados.

\begin{tabular}{lcr}
\hline & \multicolumn{2}{c}{ Sintoma (\%) } \\
\cline { 2 - 3 } Peniscopia & \multicolumn{1}{c}{ Sim } & \multicolumn{1}{c}{ Não } \\
\hline AIS & $19(33,9)$ & $174(61,9)$ \\
Clínicas e subclínicas & $25^{*}(44,7)$ & $16^{*}(5,7)$ \\
Subclínicas & $12(21,4)$ & $91(32,4)$ \\
Total $(n=337)$ & $56(100,0)$ & $281(100,0)$ \\
\hline
\end{tabular}

$p<1 / 10^{8} \quad$ Obs.: AlS = ausência de imagens suspeitas

* 3 lesões clínicas exclusivas.

\# 1 lesão clínica exclusiva. 


\section{Discussão}

Aspectos morfológicos sugestivos de infecção peniana pelo HPV foram encontrados pela histopatologia em $31,2 \%$ dos casos. O achado de lesões induzidas por HPV foi significativamente associado ao hábito de fumar, menor tempo de estabilidade conjugal e mais de uma parceira sexual.

A associação entre o tabagismo e a ocorrência de infecção pelo HPV é freqüentemente descrita em associação com lesões na mulher. Da mesma forma, nos homens o hábito de fumar pode levar a uma diminuição da resposta imunológica local, facilitando a persistência, evolução e, principalmente, as recidivas das lesões induzidas por $\mathrm{HPV}^{11}$.

É também relatado que quanto maior o número de parceiras sexuais, maior a chance de encontrar infecção pelo HPV no homem ${ }^{11}$. Observamos, neste estudo, que o fato de o homem apresentar mais de uma parceira foi suficiente para aumentar em três a quatro vezes as chances de diagnóstico de infeção por HPV, independentemente do número de parceiras relatadas.

A freqüência de infecção encontrada foi relativamente baixa em comparação com os índices já relatados, mas este estudo inclui parceiros de mulheres com neoplasia intra-epitelial genital e não condiloma acuminado. Sabe-se que a neoplasia intra-epitelial é um evento mais tardio na evolução das lesões induzidas por HPV. Parece que a cura espontânea de lesões no homem é mais freqüente que na mulher ${ }^{13}$, o que explicaria a baixa taxa de detecção nos parceiros de mulheres com NIC. Outro achado que confirma esta observação é de que quanto maior o tempo de estabilidade conjugal, menor é a chance de diagnóstico de HPV peniano, ou seja, há maior tempo para uma cura espontânea.

Outros fatores que também justificam uma menor porcentagem de diagnósticos de lesões por HPV nos homens estudados foi a utilização de atipia coilocitótica como critério único para diagnóstico histopatológico, sendo que este achado no homem parece ser focal e menos freqüente ${ }^{2,8}$. A avaliação peniscópica foi realizada livre de processo inflamatório por balanopostites inespecíficas, diminuindo em muito a presença de lesões acetobrancas ${ }^{8}$.

Acredita-se que o tempo de latência e a regressão espontânea dependem da resposta imunológica ${ }^{13}$, que pode tornar-se deficiente por influência do tabagismo, outras doenças, estresse físico ou psicológico. Na prática diária verificamos o surgimento de lesões ou recidivas relacionadas intimamente ao grau de estresse.

Desta forma, o médico tem um papel importante na orientação do casal, deixando claro o caráter endêmico desta infecção e seu baixo potencial de complicações naqueles que fazem o seguimento preventivo básico, amenizando o impacto do diagnóstico de uma DST no relacionamento do casal e enfatizando uma reavaliação na qualidade de vida, incluindo o tabagismo.

Na população estudada encontramos $37,4 \%$ de pacientes com nível de escolaridade superior, o que é relativamente alto, mas que não esteve associado à incidência de infecção pelo HPV. Os antecedentes de postectomia e de DST, fatores de risco descritos na literatura ${ }^{11}$, não estiveram associados com as lesões induzidas por HPV nesta população. Barrasso ${ }^{14}$ também não mostrou nenhuma proteção da postectomia. Apesar do antecedente de DST não ter estado associado com infecção pelo HPV, encontramos este antecedente em $27,3 \%$ dos casos, o que poderia justificar uma pesquisa das doenças mais prevalentes em parceiros de mulheres com NIC.

O melhor local de coleta da citologia na pesquisa de infecção pelo HPV no homem ainda é discutido ${ }^{1,4,8,11}$. A única que ainda persiste é a citologia uretral, que mostra resultados positivos entre 0,5 a $7 \%$. Nosso achado de $4,2 \%$ está de acordo com dados atuais e observamos que a citologia alterada ocorreu com freqüência quase quatro vezes maior em pacientes com lesões extrauretrais induzidas por HPV ${ }^{14,15}$. Mais uma vez, o tabagismo esteve associado com uma citologia suspeita para infecção pelo HPV. A não-persistência de citologia alterada em exames posteriores, após tratamento das lesões penianas ou na ausência de lesão uretral visível, sugere que muitas das citologias alteradas podem ocorrer por uma contaminação do meato uretral por lesões externas ${ }^{14}$. Por isso, empregamos a citologia uretral apenas na primeira avaliação e somente indicamos a uretroscopia quando persistirem as alterações citológicas na ausência de lesão peniana ativa ou quando estiver associada a sintomas urinários ${ }^{14,15}$.

As imagens peniscópicas não apresentam uma correlação importante com os achados histopatológicos, pois a reação ao ácido acético é inespecífica e não permite diferenciar um condiloma plano de uma neoplasia intra-epitelial, podendo ser realizadas biópsias cujo resultado é negativo e que talvez sejam desnecessárias em até $50 \%$ dos $\operatorname{casos}^{4,5,6,11,14,16}$. Encontramos $68,6 \%$ de alterações histológicas sugestivas de infecção pelo HPV em biópsias de lesões subclínicas e o achado histopatológico mais freqüente nas biópsias negativas foi a hiperqueratose $(23,3 \%)$. Este achado traduz um espessamento e uma proliferação epitelial localizada onde, não se encontrando 
nenhuma alteração citopática relacionada com o HPV, poderia indicar uma ação viral prévia sem atividade atual $1^{1,2,10,14}$, podendo ser considerada como uma 'cicatriz'. Esta hipótese poderia ser testada oportunamente através de pesquisa de DNA viral por outras técnicas, como o $\mathrm{PCR}^{1}$, mas o mais importante é sempre a avaliação clínica, pois tratamos a lesão. Se após o tratamento não houver sinais de HPV em atividade, ou seja, não houver lesões visiveis na peniscopia, o homem será considerado curado e, teoricamente, com baixo risco de transmitir o HPV ou de ter uma neoplasia no futuro ${ }^{10,13,14}$.

O grau de lesão na mulher não apresentou associação significativa com o achado de lesões induzidas por HPV no homem. Os parceiros de mulheres com LIE-BG corresponderam a 79,8\% dos casos estudados e apresentaram cerca de 25 a $32 \%$ de positividade para HPV contra 43,8\% nos parceiros de mulheres com NIC III ou neoplasia intra-epitelial vulvar (NIV) grau III. Quando avaliamos o resultado histopatológico das 229 biópsias realizadas, também observamos uma maior freqüência de positividade nos parceiros de mulheres com LIE-AG, 82,5\% contra $69,8 \%$ de positividade quando a parceira tinha LIEBG. Apesar dos parceiros, teoricamente, terem tido contato com o mesmo tipo de HPV da sua cônjuge, a manifestação clínica e histológica da infecção por HPV é imprevisivel, sofrendo influências da resposta imunológica e da região acometida. Enquanto a zona de transformação do colo uterino é o local de maior risco oncogênico, verifica-se uma baixa incidência de câncer no pênis ${ }^{2,4,13}$. Neste estudo verificamos que apenas uma de seis biópsias com NIP ocorreu em parceiro de mulher com NIC III.

Apesar de o homem ser um importante fator na disseminação do HPV, a freqüência de lesões induzidas por HPV em parceiros de mulheres com neoplasia intra-epitelial genital é baixa. Outro ponto importante é se a avaliação do homem por meio da peniscopia teria algum impacto no tratamento e seguimento destas mulheres ${ }^{7,14}$. Mas, independentemente, observamos que $90,2 \%$ das lesões clínicas apresentavam lesões subclínicas associadas e que $5,7 \%$ dos homens assintomáticos tinham lesões macroscópicas típicas de infecção por HPV.

Desta forma, acreditamos que a infecção genital pelo HPV tem de ser abordada como um problema do casal $^{7}$. No homem, esta avaliação detecta lesões induzidas por HPV em pelo menos um terço dos casos e, além de propiciar um adequado tratamento, prevenindo-se maiores seqüelas e câncer no pênis, dá-nos a oportunidade de uma orientação sensata e real, facilitando um controle do casal e diminuindo o risco de disseminação do HPV.

\section{SUMMARY}

Purpose: to evaluate risk factors and papillomavirus (HPV) associated lesions in male partners of women with genital intraepithelial neoplasia.

Patients and Methods: three hundred and thirty-seven men were evaluated by urethral cytology, peniscopy, and biopsy, if necessary. We analyzed the results and the relations to age, educational level, smoking, contact time with the present partner, age at first intercourse, number of partners, previous sexually transmitted diseases (STD), circumcision, peniscopic findings, and female lesion grade.

Results: peniscopy was positive in 144 (42,7\%) and HPV infection was diagnosed in 105 (31,2\%). Smoking, contact time with the present partner up to 6 months, and more than one previous sexual partner were associated with HPV lesions $(p<0,05)$. The urethral cytology was suspect in $4,2 \%$ and smoking, positive peniscopy or biopsy and partners of women with high-grade lesion $(p<0,05)$ were associated with the diagnosis. $72.1 \%$ of 229 biopsies were positive, independently of the peniscopic findings and women's lesion grade. Conclusions: HPV infection was diagnosed in $31.2 \%$ and was associated with smoking, contact time with the present partner up to 6 months and more than one previous sexual partner, but not with the female lesion grade, educationa level, previous STD, circumcision and peniscopic findings.

KEY WORDS: Peniscopy. Papillomavirus. Cervical intraepithelial neoplasia.

\section{Referências}

1. Abrão FS, Villa LL, Carvalho FM, Pereira EG, Focchi J, Abrão MS. Critérios diagnósticos e conduta terapêutica das infecções pelo papilomavirus no trato genital inferior. Femina 1994; 22:381-8.

2. Boon ME, Schneider A, Hogewoning CJA, Van Der Kwast TH, Bolhuis P, Kok LP. Penile studies and heterosexual partners: peniscopy, cytology, histology, and immunocytochemistry. Cancer 1988; 61:1652-9.

3. Barrasso R, De Brux J, Croissant O, Orth G. High prevalence of papillomavirus-associated penile intraepithelial neoplasia in sexual partners of women with cervical intraepithelial neoplasia. N Engl J Med 1987; 317:916-23.

4. Krebs HB, Schneider V. Human papillomavirusassociated lesions of the penis: colposcopy, cytology, and histology. Obstet Gynecol 1987; 70:299-304. 
5. Nicolau SM, Martins NV, Ferraz PE, Stávale JN, Gonçalves WJ, Baracat EC, et al. Importance of peniscopy, oncologic cytology and histopathology in the diagnosis of penile infection by human papillomavirus. Rev Paul Med 1997; 115:1330-5.

6. Sand PK, Bowen LW, Blischke SO, Ostergard DR. Evaluation of male consorts of women with genital human papilloma virus infection. Obstet Gynecol 1986; 68:679-81.

7. Bergman A, Nalick R. Prevalence of human papillomavirus infection in men: comparison of the partners of infected and uninfected women. J Reprod Med 1992; 37:710-2.

8. Palefsky JM, Barrasso R. HPV infection and disease in men. Obstet Gynecol Clin North Am 1996; 23:895-916.

9. Schneider A, Kirchmayer R, De Villiers EM, Gissmann L. Subclinical human papillomavirus infections in male sexual partners of female carriers. J Urol 1988; 140:1431-4.

10. Dias EP, Gouvea ALF, Eyer CC. Condyloma acuminatum: its histopathological pattern. Rev Paul Med 1997; 115:1383-9.
11. Hippelainen M, Syrjanen S, Hippelainen M, Koskela H, Pulkkinen J, Saarikoski S, et al. Prevalence and risk factors of genital human papillomavirus (HPV) infections in healthy males: a study on Finnish conscripts. Sex Transm Dis 1993; 20:321-8.

12. Organização Mundial da Saúde. Epi Info, a word processing, database and statistics program for public health, version 6. Geneva, 1994.

13. Hippelainen M, Hippelainen M, Saarikoski S, Syrjanen K. Clinical course and prognostic factors of human papillomavirus infections in men. Sex Transm Dis 1994; 21:272-9.

14. Barrasso R. HPV-related lesions in men. In: Munoz N, Bosch FX, Shah KV Meheus A, editores. The Epidemiology of Cervical Cancer and Human Papillomavirus. Lyon: International Agency for Research on Cancer; 1992. p. 85-92.

15. Cecchini S, Cipparrone I, Confortini M, Scuderi A, Meini L, Piazzesi G. Urethral cytology of cytobrush specimens: a new technique for detecting subclinical human papillomavirus infection in men. Acta Cytol 1988; 32:314-7.

16. Koronel R, Stefanon B, Pilotti S, Bandieramonte G, Rilke F, De Palo G. Genital human papilloma virus infection in males. A clinico-pathologic study. Tumori 1991; 77:76-82.

\section{FEBRASGO está completando}

\section{0 anos em outubro}

